\title{
Low 25-OH-vitamin D levels reflect hepatic dysfunction and are associated with mortality in patients with liver cirrhosis
}

\author{
Rafael Paternostro - Doris Wagner - Thomas Reiberger • Mattias Mandorfer - Remy Schwarzer · Monika Ferlitsch • \\ Michael Trauner · Markus Peck-Radosavljevic · Arnulf Ferlitsch
}

Received: 22 January 2016 / Accepted: 9 April 2016 / Published online: 25 November 2016 (C) The Author(s) 2016. This article is available at SpringerLink with Open Access.

\begin{abstract}
Summary
Background and aims Vitamin D deficiency is frequent in patients with cirrhosis. The aims of this study were to evaluate the relation of vitamin $\mathrm{D}$ status to portal hypertension, degree of liver dysfunction and survival.

Methods Patients with cirrhosis who have been tested for 25-OH-vitamin $\mathrm{D}$ levels were retrospectively included. Vitamin D deficiency was defined as 25-OHvitamin D levels $<10 \mathrm{ng} / \mathrm{ml}$. Child-Pugh score, model for end-stage liver disease (MELD) and available hepatic venous pressure gradient (HVPG) were recorded. Mortality was documented during follow-up.

Results A total of 199 patients were included. Prevalence of vitamin D deficiency $(<10 \mathrm{ng} / \mathrm{ml})$ was $40 \%$ (79/199), with $14 \%$ in Child-Pugh stage A, $39 \%$ in Child-Pugh stage B and $47 \%$ in Child-Pugh stage C $(p=0.001)$. Vitamin D deficiency was more common in patients with clinically significant portal
\end{abstract}

R. Paternostro $\cdot$ T. Reiberger, MD $\cdot$ M. Mandorfer, MD .

R. Schwarzer, MD · M. Ferlitsch, MD .

M. Peck-Radosavljevic, MD · A. Ferlitsch, MD

Vienna Hepatic Hemodynamic Laboratory, Divison of Gastroenterology and Hepatology, Department of Internal

Medicine III, Medical University of Vienna, Waehringer

Guertel 18-20, 1090 Vienna, Austria

arnulf.ferlitsch@meduniwien.ac.at

R. Paternostro $\cdot$ T. Reiberger, MD $\cdot$ M. Mandorfer, MD .

R. Schwarzer, MD · M. Ferlitsch, MD · M. Trauner, MD ·

M. Peck-Radosavljevic, MD · A. Ferlitsch, MD ( $ه)$

Divison of Gastroenterology and Hepatology, Department of

Internal Medicine III, Medical University of Vienna, Vienna,

Austria

arnulf.ferlitsch@meduniwien.ac.at

D. Wagner, MD

Department of Surgery, Medical University of Graz, Graz, Austria hypertension (CSPH, HVPG $\geq 10 \mathrm{~mm} \mathrm{Hg}$ ) than in patients without $(43.5 \%$ vs. $24.4 \%, p=0.025)$. Significantly more deaths were observed in patients with vitamin D deficiency $(32.9 \%, 26 / 79$ vs. $13.3 \%$, $16 / 120 ; p=0.001)$. COX regression found presence of hepatocellular carcinoma ( $p<0.001$; HR: 5.763 95\%CI:2.183-15.213), presence of CSPH ( $p=0.026$; HR: 5.487 95\%CI: 1.226-24.55) and Child-Pugh stage C ( $p=0.003$; HR:5.429 95\%CI: $1.771-16.638)$ as independent risk factors for mortality. Furthermore we could show a tendency towards group vitamin $\mathrm{D}$ deficiency being an independent risk factor ( $p=0.060$; HR: 1.86 95\%CI:0.974-3.552).

Conclusions Vitamin D levels progressively decrease in more advanced Child stages and in patients with increasing HVPG. Vitamin D deficiency might be a valuable predictor of mortality in cirrhosis.

Keywords Vitamin D · Cirrhosis · Mortality · Liver dysfunction · Portal hypertension

$\begin{array}{ll}\text { Abbreviations } & \\ \text { VIT-D } & \text { 25-OH-vitamin D3 } \\ \text { HVPG } & \text { Hepatic venous pressure gradient } \\ \text { CPS } & \text { Child-Pugh score } \\ \text { CLD } & \text { Chronic liver disease } \\ \text { CSPH } & \text { Clinical significant portal hyperten- } \\ & \text { sion } \\ \text { D-DEF } & \text { VIT-D levels }<10 \mathrm{ng} / \mathrm{ml} \\ \text { D-NON-DEF } & \text { VIT-D levels }>10 \mathrm{ng} / \mathrm{ml} \\ \text { HCC } & \text { Hepatocellular carcinoma } \\ \text { kPa } & \text { Kilo Pascal } \\ \text { TE } & \text { Transient elastography } \\ \text { HCV } & \text { Hepatitis C virus } \\ \text { NAFLD } & \text { Nonalcoholic fatty liver disease } \\ \text { PHT } & \text { Portal hypertension } \\ \text { HE } & \text { Hepatic encephalopathy } \\ \text { HRS } & \text { Hepatorenal syndrome }\end{array}$



HBV
Hepatitis B virus
SBP
Spontaneous bacterial peritonitis
DBP
D-binding protein

\section{Introduction}

Liver cirrhosis is the cause of around 170,000 deaths per year in Europe, whereas liver cancer is responsible for around 47,000 deaths per year in the EU [1], while a recent report suggests that even this might be an underestimation [2]. There are several risk factors for developing complications of cirrhosis such as ascites, hepatic encephalopathy, and GI bleeding. Portal hypertension is the triggering factor for those complications most of the time since it decreases liver function and therefore encourages complications to begin [3].

The liver plays a crucial role in the biosynthesis of active vitamin-D3 (i. e., calcitriol or 1,25-OH vitaminD3) via hydroxylation to 25-OH-vitamin-D3. Although the final hydroxylation step to produce 1,25-OH-vitamin-D3 is done in the kidney, 25-OH-vitamin-D3 (= VIT-D)—as synthesized by the liver-is the most commonly used biomarker to measure vitamin-D status in patients, given its half-life [4]. Other than that 25-OH-vitamin-D3 is also a key modulator of bone growth and remodeling [5].

In a large Austrian multicenter study, up to $42 \%$ of patients were found with VIT-D levels $<20 \mathrm{ng} / \mathrm{ml}$ [6]. Various studies have shown that VIT-D deficiency (defined as VIT-D $<20 \mathrm{ng} / \mathrm{ml}$ in those studies) has an even higher prevalence in patients with CLD (chronic liver disease) ranging from 64 to 92\% [7-9]. Especially in patients with cirrhosis VIT-D deficiency seems to be seen with a significant higher prevalence than in those without shown in a study performed by Fisher et al. [8] where $86 \%$ of cirrhotic patients had VITD deficiency compared to only $49 \%$ without cirrhosis. Also an inverse correlation between VIT-D status and severity of the liver disease was found by showing that patients with Child-Pugh score C had significantly lower mean VIT-D levels that those patients found with Child-Pugh score A $(9.0 \pm 4.0$ in CPS C vs. $18.3 \pm 6.7 \mathrm{ng} / \mathrm{ml}$ in CPS A).

Four studies using different definitions for VIT-D deficiency have evaluated the relationship between VIT-D levels of cirrhotic patients and mortality; significant correlations were found. However, conflicting results regarding the cut-off serum level for VIT-D as an independent risk factor for mortality were reported [10-13].

The aim of this study was to investigate how VIT-D influences mortality in a large cohort of patients and especially if it stands as an independent risk factor for mortality since the four studies performed reported conflicting results. Furthermore as portal hypertension is the main risk factor in the course of patients with cirrhosis we investigated the HVPG and its correlation with VIT-D levels to find whether VIT-D could be used as a noninvasive tool to predict portal pressure.

\section{Materials and methods}

\section{Patients}

In this retrospective multicenter study 199 patients diagnosed with liver cirrhosis that had VIT-D level available were included. A total of 100 consecutive patients were included from the Medical University of Graz and 99 consecutive patients were included from the Medical University of Vienna. Inclusion criteria were the following: available VIT-D level at time of study inclusion, available Child-Pugh score, available MELD score [14], no VIT-D supplementation of any kind at study inclusion and available follow-up for mortality. VIT-D levels were measured with routine clinical analyses in all patients during outpatient visits or administration to the ward. All patients have been diagnosed with cirrhosis based on either clinical, radiological parameters or on liver histology. Supplementation of VIT-D after study inclusion was left to the discretion of the physician following the patient in routine care and was not part of the study. Patients that underwent liver transplantation were censored at the day of transplantation. Patients selected for HVPG were cirrhotic patients routinely scheduled for response guided NSBB therapy or risk assessment prior to liver resection.

\section{Measurement of 25-OH-vitamin D}

Blood used for analysing 25-OH-vitamin-D3 was drawn during routine blood-analysis when patients visited the outpatient clinic or at the ward. Chemiluminescence Immunoassay was used for exact measurement of 25-OH-vitamin-D3 (DiaSorin ${ }^{\mathrm{TM}}$, Liaision $\mathrm{XL}$, Saluggia, Italy). Reference range was $30-100 \mathrm{ng} / \mathrm{ml}$. Vitamin D deficiency is defined as 25-OH-vitamin-D3 levels below $20 \mathrm{ng} / \mathrm{ml}$ [15-18] although several studies used different definitions of deficiency and took levels $<10 \mathrm{ng} / \mathrm{ml}$ as deficient $[12,19]$. Insufficiency is defined as $20-30 \mathrm{ng} / \mathrm{ml}$ [15-18] but once more several studies already used $>20 \mathrm{ng} / \mathrm{ml}$ as the cut-off for normal VIT-D status in patients with CLD [10, 20, 21].

\section{HVPG measurement}

The right internal jugular vein was accessed under ultrasound guidance and local anaesthesia with Seldinger technique using a catheter introducer set (8.5 F, Arrow International, Reading, PA, USA). Then a balloon catheter (Pejcl Medicintechnik, Austria) [22] was chosen to cannulate the liver vein via the transjugular access as described previously [23]. CSPH was defined as $\geq 10 \mathrm{~mm} \mathrm{Hg}$ [24]. 
Table 1 Patients characteristics with and without vitamin D deficiency

\begin{tabular}{|c|c|c|c|c|c|}
\hline Patients characteristics & $\begin{array}{l}\text { All patients } \\
(n=199)\end{array}$ & $\begin{array}{l}\text { Correlation (absolute } \\
\text { VIT-D [ng/ml]) } \\
P \text { value }\end{array}$ & VIT-D $\leq 10 \mathrm{ng} / \mathrm{ml}(n=79)$ & $\begin{array}{l}\text { VIT-D > } 10 \mathrm{ng} / \mathrm{ml} \\
(n=120)\end{array}$ & $\begin{array}{l}P \text { Value } \\
<10 \mathrm{ng} / \mathrm{ml} \text { vs } \\
>10 \mathrm{ng} / \mathrm{ml}\end{array}$ \\
\hline $\begin{array}{l}\text { 25-Hydroxyvitamin D3 } \\
\text { [ng/ml], median (95\%Cl) }\end{array}$ & $11.98(4-31.33)$ & - & $6.41(3.25-9.5)$ & $17.4(10.42-33)$ & $<0.001$ \\
\hline Age, median $(95 \% \mathrm{Cl})$ & $57(38-69)$ & $\begin{array}{l}0.037 \\
(r=0.148)\end{array}$ & $56(38-72)$ & $58(38-69)$ & 0.072 \\
\hline \multicolumn{6}{|l|}{ Gender, $n(\%)$} \\
\hline Male & $147(73.9 \%)$ & \multirow{2}{*}{$\begin{array}{l}0.146 \\
(r=-0.104)\end{array}$} & $57(72.2 \%)$ & $90(75 \%)$ & 0.742 \\
\hline Female & $52(26.1 \%)$ & & $22(27.8 \%)$ & $30(25 \%)$ & - \\
\hline \multicolumn{6}{|l|}{ CPS, $n$ (\%) } \\
\hline$A$ & $57(28.6 \%)$ & \multirow{3}{*}{$\begin{array}{l}<0.001 \\
(r=-0.235)\end{array}$} & $11(13.9 \%)$ & $46(38.3 \%)$ & \multirow[t]{3}{*}{0.001} \\
\hline B & $68(34.2 \%)$ & & $31(39.2 \%)$ & $37(30.8 \%)$ & \\
\hline C & 74 (37.2\%) & & $37(46.8 \%)$ & 37 (30.8\%) & \\
\hline $\mathrm{HVPG}$, mean $\pm \mathrm{SD}$ & $16 \pm 6.3^{\mathrm{a}}$ & $\begin{array}{l}<0.001 \\
(r=-0.360)\end{array}$ & $19 \pm 6.13$ & $14 \pm 5.94$ & $<0.001$ \\
\hline \multicolumn{6}{|l|}{$\mathrm{CSPH}, n(\%)$} \\
\hline Yes & $156(79.1 \%)$ & \multirow{2}{*}{$\begin{array}{l}0.001 \\
(r=-0.235)\end{array}$} & $68(87.2 \%)$ & $88(74 \%)$ & \multirow[t]{2}{*}{0.025} \\
\hline No & $41(20.9 \%)$ & & $10(12.8 \%)$ & $31(26 \%)$ & \\
\hline \multicolumn{6}{|l|}{$H C C, n(\%)$} \\
\hline Yes & $27(13.6 \%)$ & \multirow{2}{*}{$\begin{array}{l}0.091 \\
(r=-0.120)\end{array}$} & $10(12.7 \%)$ & $17(14.2 \%)$ & \multirow[t]{2}{*}{0.835} \\
\hline No & $172(86.4 \%)$ & & $69(87.3 \%)$ & $103(85.8 \%)$ & \\
\hline MELD, median $(95 \% \mathrm{Cl})$ & $12(6.43-24)$ & $\begin{array}{l}0.002 \\
(r=-0.223)\end{array}$ & $13(6.9-26.6)$ & $11(6.4-20)$ & 0.003 \\
\hline $\begin{array}{l}\text { Bilirubin [mg/dl], median } \\
(95 \% \mathrm{Cl})\end{array}$ & $1.85(0.48-15.17)$ & $\begin{array}{l}0.004 \\
(r=-0.203)\end{array}$ & $2.2(0.48-23.13)$ & $1.54(0.5-5.6)$ & 0.007 \\
\hline Albumin $[\mathrm{g} / \mathrm{l}]$ mean $\pm \mathrm{SD}$ & $33.9( \pm 6.2)$ & $\begin{array}{l}<0.001 \\
(r=0.274)\end{array}$ & $31.8( \pm 5.74)$ & $35.34( \pm 6.15)$ & $<0.001$ \\
\hline $\begin{array}{l}\text { Prothrombin, time [\%], me- } \\
\text { dian }(95 \% \mathrm{Cl})\end{array}$ & $62(31-106)$ & $\begin{array}{l}<0.001 \\
(r=0.305)\end{array}$ & $56(25-41)$ & $67(36.8-107.1)$ & 0.001 \\
\hline $\begin{array}{l}\text { Transient elastography }[\mathrm{kPa}] \text {, } \\
\text { median }(95 \% \mathrm{Cl})\end{array}$ & $44(12.6-75)^{b}$ & $\begin{array}{l}0.003 \\
(r=-0.425)\end{array}$ & $69.5(11.66-75)$ & $32.5(12.33-75)$ & 0.003 \\
\hline $\begin{array}{l}\text { Days of follow-up, median } \\
(95 \% \mathrm{Cl})\end{array}$ & $419(22-1048)$ & $\begin{array}{l}0.189 \\
(r=0.093)\end{array}$ & $294(11-1027)$ & $446(22-1049)$ & 0.109 \\
\hline Death, $n(\%)$ & $42(21.1 \%)$ & $\begin{array}{l}0.002 \\
(r=-0.216)\end{array}$ & $26(32.9 \%)$ & $16(13.3 \%)$ & 0.001 \\
\hline
\end{tabular}

\section{Transient elastography}

Transient elastography (Fibroscan, Echosense, France) correlates well with grade of fibrosis/cirrhosis [25]. It was performed in a supine position with the right arm resting behind the head of the patient before measurement of HVPG. At least 10 values were performed for each patient and the median value was then taken into account. Only values with an IQR/M $<30 \%$ were taken in account for statistical analysis [26].

\section{Statistical analysis}

Continuous variables were reported as mean \pm standard deviation (SD) or median $(95 \%$ interquartile range [IQR]), and categorical variables were reported as number $(n)$ of patients with the certain characteristic (proportion of patients with the certain char- acteristics [\%]). Student $t$ test was used for group comparisons of normally distributed data, and the Mann-Whitney U test where data was not normally distributed. Pearson's Chi-Square test or Fishers exact test was performed to conduct group comparisons for categorical data. The impact of VIT-D on mortality incidence and transplant-free survival was analyzed using semi-parametric proportional hazard COX models. To minimize problems of multilinearity the following covariates were chosen: age, HCC yes/no, CSPH, CPS, status D-DEF/D-NON-DEF. Child-Pugh score was chosen over MELD since it covers more aspects of cirrhosis (ascites, hepatic encephalopathy, albumin and prothrombin-time). Patients entered the model on the day when blood was drawn for analysing VIT-D levels and were followed until either (I) death (II) liver transplantation or (III) lost of follow-up. Patients who received liver transplantation 

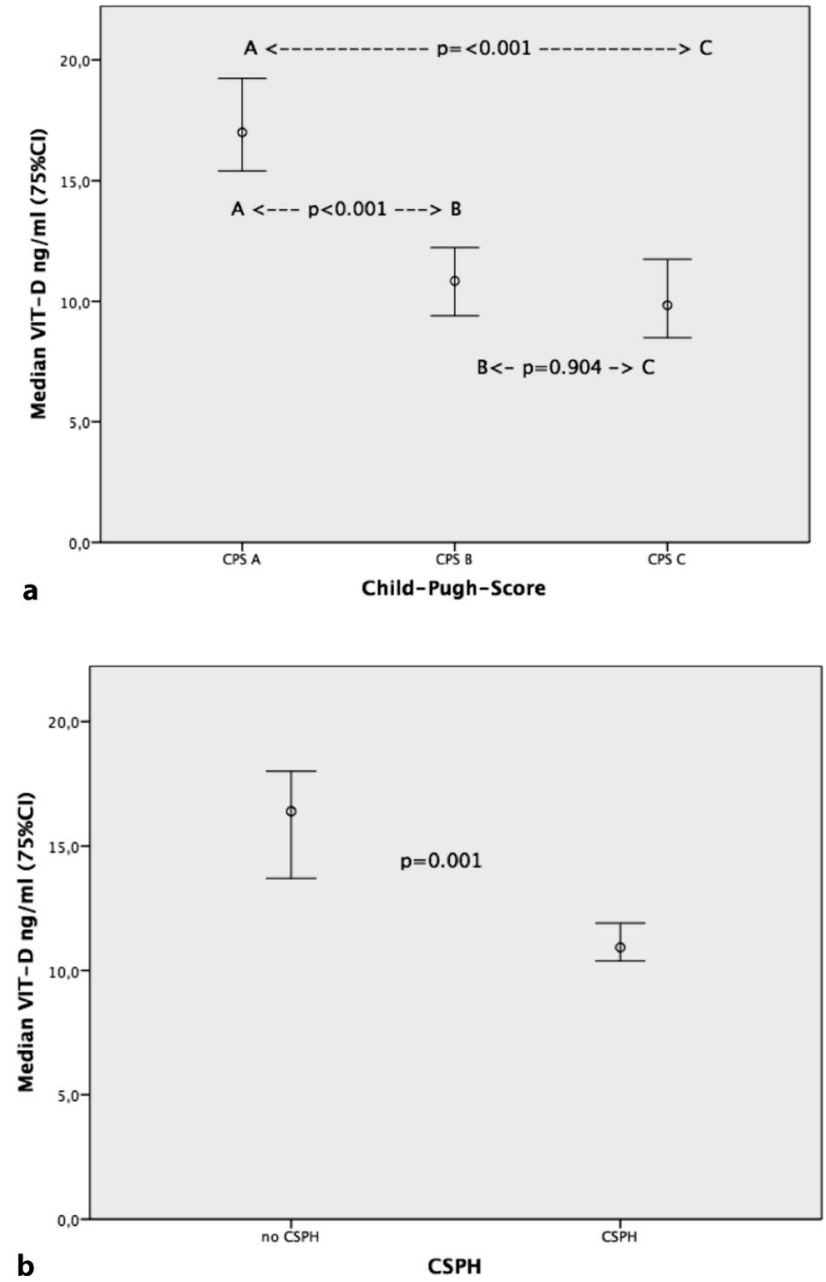

Fig. 1 a Median 25-OH-vitamin-D3 (VIT-D) levels over groups of Child-Pugh score stages. b Median VIT-D levels in patients with and without clinical significant portal hypertension $(\mathrm{CSPH})$

were censored at the day of surgery. A multiple linear regression model was used to find independent covariates that influence absolute VIT-D levels (independent variable: absolute VIT-D levels). A binary logistic model was conducted to find independent risk factors of being found with VIT-D levels below $10 \mathrm{ng} / \mathrm{ml}$ (independent variable: D-DEF yes/no). Kaplan-Meier curves are shown for comparison of survival time in patients. Log-rank test was conducted to find difference in mean survival times. Two sided $p$ values $<0.05$ were considered as statistically significant. The IBM SPSS 22.0 statistic software (SPSS Inc., Armonk, NY, USA) was used for all statistical analysis.

\section{Results}

In total, 199 patients were included in the study. For main patient characteristics see Table 1 . We classified patients into two groups for all statistical analyses: VIT-D $<10 \mathrm{ng} / \mathrm{ml}=$ D-DEF and VIT-D $>10 \mathrm{ng} / \mathrm{ml}=$ D-NON-DEF.

\section{Vitamin $D$ and cirrhosis}

Of patients, $28.6 \%$ were found in CPS A, $34.2 \%$ in CPS B and $37.2 \%$ in CPS C. Significant correlation with absolute VIT-D levels was found $(p<0.001$, $r=-0.251)$. We also compared median values in all three groups and found significant difference (CPS A: $17 \mathrm{ng} / \mathrm{ml}$, range $11.1-26$, CPS $B: 10.8 \mathrm{ng} / \mathrm{ml}$, range 7.1-15.5, CPS C: $9.8 \mathrm{ng} / \mathrm{ml}$, range $6.1-18.2$; A vs. B $p<0.001$; A vs. C $p<0.001$; B vs. C $p=0.904$, see Fig. 1a). Also absolute VIT-D levels significantly correlated with MELD score ( $p=0.002, \mathrm{r}=-0.223)$. When separated into groups MELD score $>10$ vs $\leq 10$ significant differences in median VIT-D levels were found $(11.2 \mathrm{ng} / \mathrm{ml}$ vs. $14.6 \mathrm{ng} / \mathrm{ml} ; p=0.013)$. Significant correlation between VIT-D values and prothrombin time values was found $(p<0.001, \mathrm{r}=0.305)$. Univariate binary logistic regression (independent variable: prothrombin time $<60 \%$ /prothrombin time $>60 \%$, covariate: status D-DEF/D-NON-DEF) found being in 10 -DEF as a risk factor for group "prothrombin time $<60 \%$ " ( $p=0.002$; OR: 2.528 95\%CI: 1.404-4.552). Also Mann-Whitney $U$ test found significant differences in median VIT-D values between the two subgroups ("prothrombin time $>60 \%$ " $14.4 \mathrm{ng} / \mathrm{ml}$ vs. "prothrombin time $<60 \%$ " $9.2 \mathrm{ng} / \mathrm{ml} ; p<0.001)$.

\section{Vitamin $D$ and portal pressure}

In total, $78.4 \%$ of all patients were found with clinical significant portal hypertension (CSPH). We found significant correlations of absolute VIT-D with HVPG values $(p<0.001, \mathrm{r}=-0.360)$ as well as presence of CSPH ( $p=0.001, \mathrm{r}=-0.235$ ). Also significant differences in median VIT-D levels were found between the CSPH vs. no-CSPH group $(10.9 \mathrm{ng} / \mathrm{ml}$ vs. $16.4 \mathrm{ng} / \mathrm{ml}, p=0.001$, see Fig. 1b). When comparing groups D-DEF/D-NONDEF significantly higher distribution of CSPH within the D-DEF group could be found ( $87 \%$ of D-DEF had CSPH vs only $74 \%$ of D-NON-DEF patients; $p=0.025$ ). ROC analysis found an AUC of $0.667(p=0.001)$ for the prediction of CSPH using VIT-D.

\section{Vitamin D and mortality}

In all, 42/199 (21.1\%) patients died during follow-up. Univariate correlation analysis found the following parameters significantly associated with death: albumin $(p=0.002, \mathrm{r}=-0.223)$, MELD $(p=0.006 ; \mathrm{r}=$ $0.194)$, HVPG ( $p=0.003, \mathrm{r}=0.210)$, CPS $(p=0.001, \mathrm{r}=$ $0.238)$ and absolute VIT-D ( $p=0.002, \mathrm{r}=-0.216)$. Significantly more patients died in group D-DEF 26/79 $(=32.9 \%)$ than in group D-NON-DEF $16 / 120(=13.3 \%)$ $(p=0.001)$. Significant difference in median VIT-D levels in groups "death" vs. "no death" was found $(p=$ $0.002 ; 7.95 \mathrm{ng} / \mathrm{ml}[4-32.3]$ vs. $12.8 \mathrm{ng} / \mathrm{ml}[4.1-31.3])$. COX regression (covariates: age, HCC yes/no, CSPH, CPS, status D-DEF/D-NON-DEF) found presence of HCC $(p<0.001$; HR: 5.763 95\%CI: 2.183-15.213), 


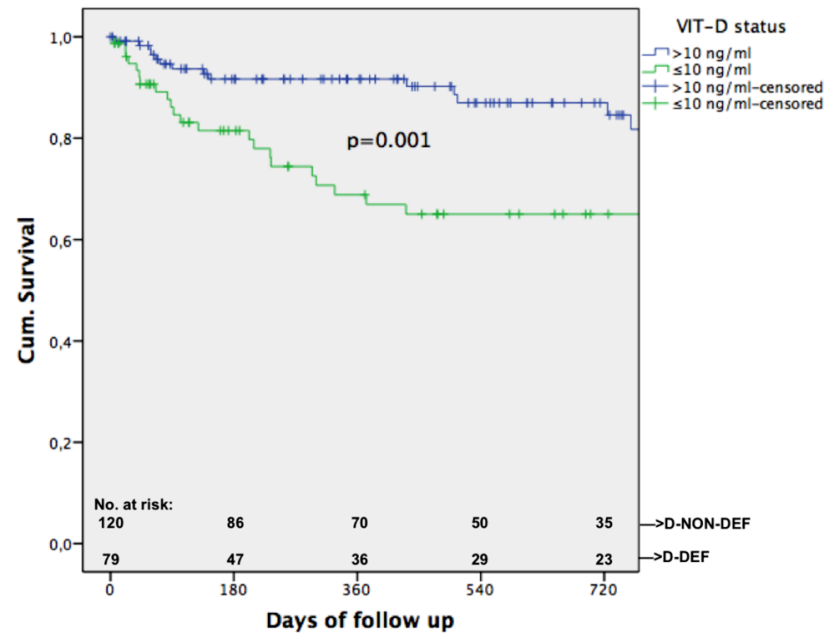

Fig. 2 Kaplan-Meier curve shown for all patients separated in groups with vitamin-D-deficiency (D-DEF) and without ( $D-N O N$ $D E F)$
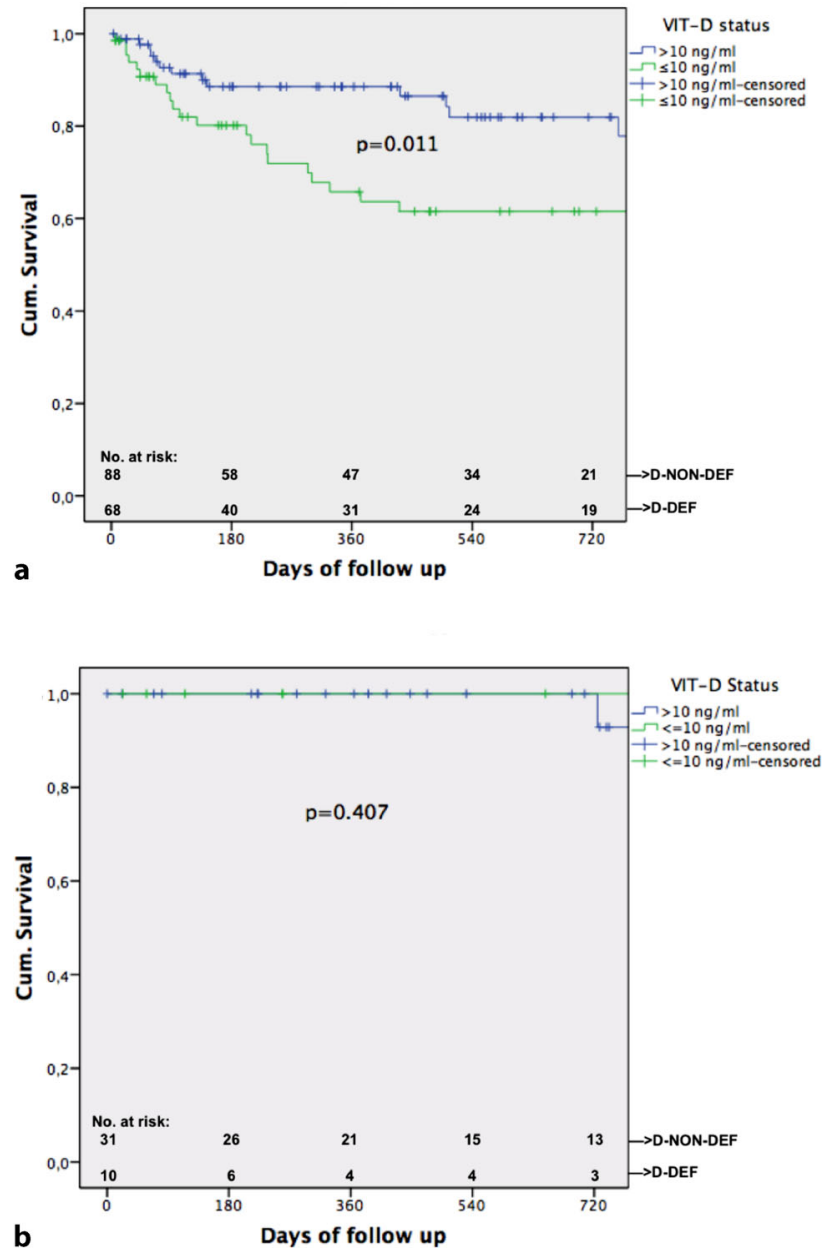

Fig. 3 Kaplan-Meier curve shown for patients with (a) and without (b) clinical significant portal hypertension (CSPH) separated in groups with vitamin-D deficiency (D-DEF) and without $(D-N O N-D E F)$ presence of CSPH ( $p=0.026$; HR: 5.487 95\%CI: 1.226-24.55) and CPS C ( $p=0.003$; HR:5.429 95\%CI: 1.771-16.638) as independent risk factors for mortality. A trend towards being in group D-DEF could be seen ( $p=0.060$; HR: 1.86 95\%CI: 0.974-3.552). Kaplan-Meier curve found significant a difference in survival in groups D-DEF/D-NON DEF ( $p=0.001$, see Fig. 2). Furthermore we analyzed subgroups and the influence of D-DEF status in their survival (see Figs. 3 and 4). ROC analysis determined an AUC of 0.653 $(p=0.002)$ for the predicting value of absolute VIT-D levels for death.

\section{Vitamin D and transient elastography}

A total of 48 patients had valid (IQR $<30 \%$ of total $\mathrm{kPa}$ ) TE tracings. Significant different values were found in groups D-DEF/D-NON-DEF (Table 1). Correlation analysis found significant correlation between absolute VIT-D values and stiffness ( $p=0.003, \mathrm{r}=-0.425)$.

\section{Multivariate analysis}

Linear regression (independent variable: absolute VIT-D values; covariates model 1: age, HCC, CSPH, MELD; model 2: age, HCC, CSPH, CPS) found CSPH as an independent risk factor for low absolute VIT-D levels in both models (model 1: $p=0.017$, model $2: p=$ $0.035)$. Multivariate analysis found that patients found with CPS B ( $p=0.004$; OR: 3.317 95\%CI: 1.466-7.504) and CPS C ( $p=0.001$; OR:4.091 95\%CI:1.836-9.117) are at higher risk for being found with VIT-D levels below $<10 \mathrm{ng} / \mathrm{ml}$.

\section{Discussion}

Our study investigated the correlation of Vitamin D in portal hypertension (documented by HVPG) and its predictive value in patients with liver cirrhosis in a large cohort of patients. We could show up to $94 \%$ of patients with liver cirrhosis suffer from VIT-D deficiency when taking $>30 \mathrm{ng} / \mathrm{ml}$ as normal level, whereas $76.4 \%$ where found deficient when taking $<20 \mathrm{ng} / \mathrm{ml}$ as the cut-off and $40 \%$ with levels $<10 \mathrm{ng} / \mathrm{ml}$. This results are in line with the literature when $20 \mathrm{ng} / \mathrm{ml}$ was taken as a cut-off; Stokes et al. [11] reported that $86 \%$ of cirrhotic patients were deficient and a recent study found $68.9 \%$ of patients with VIT-D $<10 \mathrm{ng} / \mathrm{ml}$ [13]. Another study performed in Austria by Putz-Bankuti et al. [10] found $71 \%$ deficient $(<20 \mathrm{ng} / \mathrm{ml})$ patients so the real number might be somewhere around $80 \%$. Those results also fit the literature for patients with chronic liver disease (CLD) where Lange et al. [21] found $66 \%$ of chronic HCV patients in a deficient state. Therefore it seems that presence of cirrhosis severely increases prevalence of VIT-D deficiency. Regarding correlation between grade of liver dysfunction and VIT-D we found significant differences between CPS A vs. B and A vs. C, 

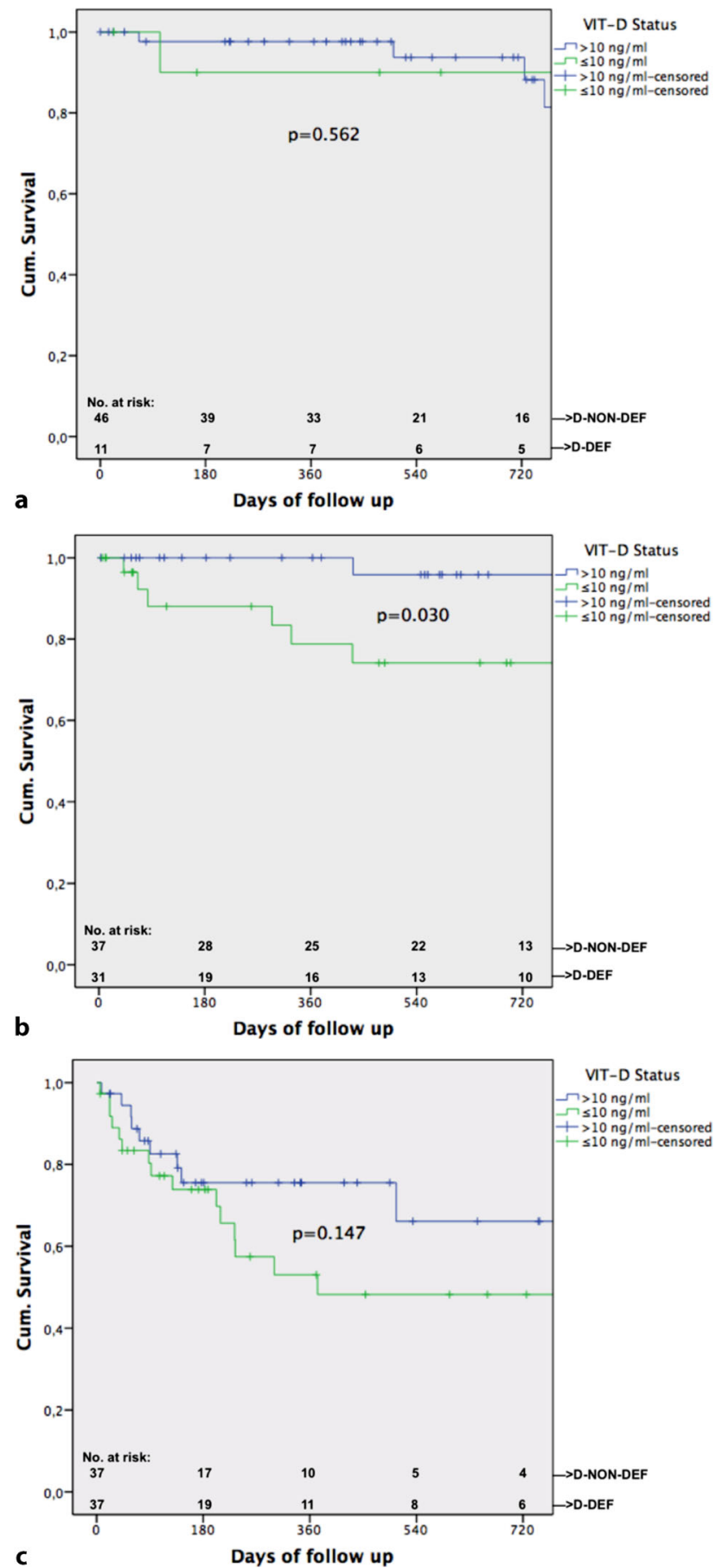

Fig. 4 Kaplan-Meier curve for each Child-Pugh score (CPS) stage separated in groups with vitamin-D deficiency ( $D-D E F)$ and without (D-NON-DEF)

and could therefore enhance the results found in other studies [10, 13]. Regarding MELD scores we could confirm the results found in Putz Bankuti et al. [10] and Finkelmeier et al. [13] that absolute VIT-D significantly correlated with MELD score.

Regarding HVPG we confirm the results found by Trepo et al. [12] published in 2013 that higher HVPG values are associated with low VIT-D. Furthermore we found $\mathrm{CSPH}$ as an independent risk factor for low absolute VIT-D in multivariate analysis. Also median VIT-D levels were significantly lower in the CSPH group (Fig. 1b) and significantly more patients with D-DEF status were found in the CSPH group (Table 1). We could for the first time show that VIT-D significantly inversely correlates with absolute transient elastography values. Significant differences in median TE values could be found in groups D-DEF/D-NONDEF (Table 1). This confirms the results by Trepo et al. [12] where a significant association between absolute VIT-D steatosis and fibrosis was found. This underlines the possible potential value of VIT-D as a non-invasive parameter for staging cirrhosis.

Regarding mortality significantly lower median VIT$\mathrm{D}$ was found in patients who died during follow-up $(p=0.002)$. We also found presence of HCC, presence of CSPH and CPS C as independent risk factors for mortality. Although D-DEF marginally missed significance we could show a trend towards vitamin D status as an independent risk factor for mortality (Table 2). Therefore our results are in line with the results found in previous studies that VIT-D is a valuable predictor for survival [10-13, 27]. We could also show that D-DEF seems to be a good cut-off for mortality given our Kaplan-Meier curve for all patients (Fig. 2). For the first time we could also show that VITD seems to be a significant factor regarding survival when analyzing subgroup of patients with CSPH and patients with CPS B (Figs. 3 and 4). Interestingly in patients with no CSPH and also in those with CPS A D-DEF was not a significant factor associated with survival of those patients; hence this could be due to their still rather intact liver. CPS $\mathrm{C}$ also did not reach significance in this subgroup analysis, but our graph fairly shows that those patients seem to decompensate very shortly after inclusion due to their severe liver damage. Therefore it seems D-DEF is not able to predict their outcome given their end-stage disease status.

Stokes et al. very well described the function of VIT$\mathrm{D}$ in liver disease in their review published in 2012 [4]. Reduced exogenous exposure of patients to VITD sources, intestinal malabsorption of dietary VITD3, reduced endogenous production of VIT-D binding protein and albumin, impaired hepatic hydroxylation of 1,25-OH-vitamin D3 to 25-OH-vitamin D3 and increased catabolic removal of 25-OH-vitamin D3 are described as responsible mechanisms for the VIT$\mathrm{D}$ deficiency in cirrhosis [4]. An association between liver-related complications and low VIT-D levels have been shown by Trepo et al. [12], Wong GL et al. [28] and most recently by Finkelmeier et al. [13]. Trepo et al. described a significantly higher rate of PHT complications (such as ascites, HE or HRS) when patients were found with VIT-D levels $<10 \mathrm{ng} / \mathrm{ml}$; hence we chose our group D-DEF $(<10 \mathrm{ng} / \mathrm{ml})$ to be able to properly compare results. Wong et al. [28] found that in a large prospective HBV cohort $(n=426,11 \%$ found with cirrhosis, $89 \%$ with CLD) patients that developed clinical events had significantly lower VIT- 
Table 2 Multivariate stepwise backwards COX regression analysis regarding factors independently associated with mortality

\begin{tabular}{|c|c|c|c|}
\hline Co-Variates & $p$-value & Hazard ratio & $95 \% \mathrm{Cl}$ \\
\hline Presence of HCC & $<0.001$ & 5.763 & $2.183-15.213$ \\
\hline $\begin{array}{l}\text { Presence of } \\
\text { CSPH }\end{array}$ & 0.026 & 5.487 & $1.226-24.55$ \\
\hline CPS C & 0.003 & 5.429 & $1.771-16.638$ \\
\hline Status D-DEF & 0.060 & 1.86 & $0.974-3.552$ \\
\hline
\end{tabular}

Co-variates: age, HCC yes/no, CSPH, CPS, status D-DEF/D-NON-DEF VIT-D 25-OH-vitamin-D3, CPS Child-Pugh score , HVPG hepatic venous pressure gradient, $C S P H$ clinical significant portal hypertension, $H C C$ hepatocellular carcinoma, MELD model for end-stage liver disease

D levels than those who did not. Finkelmeier et al. [13] on the other hand found that patients with diagnosed SBP had significant lower VIT-D levels than those without. Hence the previous results regarding mortality and decompensation are therefore in line with the results found in our study. In a recently published paper by Lai JC et al. [29] the relationship between VIT-D levels, albumin and vitamin-D binding protein (DBP) was shown. They found that cirrhotics with synthetic dysfunction (= albumin $<3.5 \mathrm{~g} / \mathrm{dl}$ ) tend to have lower total and free VIT-D as well as DBP levels but higher percentage of free VIT-D. They stated that "total VIT-D is not an accurate marker of true Vitamin D status" and furthermore proposed that "supplementation may not be an adequate therapy for bone disease in cirrhosis". Regarding our study we therefore propose that patients found with VIT-D under $10 \mathrm{ng} / \mathrm{ml}$ should be screened and evaluated even more tightly given the results by Lai JC et al. Hence even though their VIT-D status might not be accurate we nevertheless found increased risk for adverse events in those lower than $10 \mathrm{ng} / \mathrm{ml}$. Furthermore we investigated VIT-D as a noninvasive marker for grade of disease and prediction of mortality and did not aim to evaluate its role in cirrhotic bone disease.

In conclusion there is a strong trend towards VITD levels predicting mortality in patients with cirrhosis and a $10 \mathrm{ng} / \mathrm{ml}$ cut-off seems to discriminate patients at higher risk for mortality. Moreover VIT-D seems to be an accurate marker of reflecting liver dysfunction and is a good synthesis-related parameter. Although we found significant results regarding the association of VIT-D and transient elastography, given the small number of patients, further prospective studies are needed in that direction to prove the possible value of a combined noninvasive screening marker. Prediction of CSPH through VIT-D cannot be made.

Open access funding provided by Medical University of Vienna.

\section{Compliance with Ethical Standards}

Conflict of interest R. Paternostro, D. Wagner, T. Reiberger, M. Mandorfer, R. Schwarzer, M. Ferlitsch, M. Trauner,
M. Peck-Radosavljevic and A. Ferlitsch declare that they have no competing interests.

Ethical standards The study was performed in accordance to the current version of Helsinki Declaration and approved by the local Ethics Committee of the Medical University of Vienna and the Medical University of Graz. Since this was a retrospective study no informed consent was needed.

Open Access This article is distributed under the terms of the Creative Commons Attribution 4.0 International License (http://creativecommons.org/licenses/by/4.0/), which permits unrestricted use, distribution, and reproduction in any medium, provided you give appropriate credit to the original author(s) and the source, provide a link to the Creative Commons license, and indicate if changes were made.

\section{References}

1. Blachier M, Leleu H, Peck-Radosavljevic M, et al. The burden of liver disease in Europe: a review of available epidemiological data. J Hepatol. 2013;58(3):593-608.

2. Asrani SK, Larson JJ, Yawn B, et al. Underestimation of liverrelated mortality in the United States. Gastroenterology. 2013;145(2):375-382. e1-2.

3. D’Amico G, Garcia-Tsao G, Pagliaro L. Natural history and prognostic indicators of survival in cirrhosis: a systematic review of 118 studies. JHepatol. 2006;44(1):217-31.

4. Stokes CS, Volmer DA, Grunhage F, et al. Vitamin D in chronic liver disease. Liver Int. 2013;33(3):338-52.

5. Plum LA, DeLuca HF. Vitamin D, disease and therapeutic opportunities. NatRev Drug Discov. 2010;9(12):941-55.

6. Muschitz C, Kocijan R, Stutz V, et al. Vitamin D levels and comorbidities in ambulatory and hospitalized patients in Austria. Wien Klin Wochenschr. 2015;127(17-18):675-84.

7. Arteh J, NarraS, Nair S. Prevalence of vitamin D deficiency in chronic liver disease. Dig Dis Sci. 2010;55(9):2624-8.

8. Fisher L, Fisher A. Vitamin D and parathyroid hormone in outpatients with noncholestatic chronic liver disease. Clin Gastroenterol Hepatol. 2007;5(4):513-20.

9. Chen CC, Wang SS, Jeng FS, et al. Metabolic bone disease of liver cirrhosis: is it parallel to the clinical severity of cirrhosis? J Gastroenterol Hepatol. 1996;11(5):417-21.

10. Putz-Bankuti C, Pilz S, Stojakovic T, et al. Association of 25hydroxyvitamin D levels with liver dysfunction and mortality in chronic liver disease. Liver Int. 2012;32(5):845-51.

11. StokesCS, KrawczykM, ReichelC, etal. VitaminDdeficiency is associated with mortality in patients with advanced liver cirrhosis. Eur JClin Invest. 2014;44(2):176-83.

12. Trepo E, Ouziel R, PradatP, etal. Marked 25-hydroxyvitamin $\mathrm{D}$ deficiency is associated with poor prognosis in patients with alcoholic liver disease. J Hepatol. 2013;59(2):344-50.

13. Finkelmeier F, Kronenberger B, Zeuzem S, et al. Low 25Hydroxyvitamin D Levels Are Associated with Infections and Mortality in Patients with Cirrhosis. PLOS ONE. 2015;10(6):e0132119.

14. Kamath PS, Kim WR. The model for end-stage liver disease (MELD). Hepatology (Baltimore Md). 2007;45(3):797-805.

15. Holick MF. High prevalence of vitamin D inadequacy and implications for health. Mayo Clin Proc. 2006;81(3):353-73.

16. Bischoff-Ferrari HA, Giovannucci E, Willett WC, et al. Estimation of optimal serum concentrations of 25-hydroxyvitamin D for multiple health outcomes. Am J Clin Nutr. 2006;84(1):18-28.

17. MalabananA, Veronikis IE, HolickMF. Redefining vitaminD insufficiency. Lancet. 1998;351(9105):805-6. 
18. Dawson-Hughes B, Heaney RP, HolickMF, et al. Estimates of optimalvitamin Dstatus. Osteoporos Int. 2005;16(7):713-6.

19. Malham M, Jørgensen Sø P, Ott P, et al. Vitamin D deficiency in cirrhosis relates toliver dysfunction rather than aetiology. World J Gastroenterol. 2011;17(7):922-5.

20. Bitetto D, Fattovich G, Fabris C, et al. Complementary role of vitamin $\mathrm{D}$ deficiency and the interleukin-28B rs $12979860 \mathrm{C} / \mathrm{T}$ polymorphism in predicting antiviral response in chronic hepatitis C. Hepatology (Baltimore Md). 2011;53(4):1118-26.

21. Lange CM, Bojunga J, Ramos-Lopez E, et al. Vitamin $\mathrm{D}$ deficiency and a CYP27B1-1260 promoter polymorphism are associated with chronic hepatitis $\mathrm{C}$ and poor response to interferon-alfa based therapy. J Hepatol. 2011;54(5):887-93.

22. Ferlitsch A, Bota S, Paternostro R, et al. Evaluation of a new balloon occlusion catheter specifically designed for measurement of hepatic venous pressure gradient. Liver Int. 2015; doi:10.1111/liv.12783.

23. Ferlitsch M, Reiberger T, Hoke M, et al. Von Willebrand factor as new noninvasive predictor of portal hypertension, decompensation and mortality in patients with liver cirrhosis. Hepatology (Baltimore Md). 2012;56(4):1439-47.
24. Peck-Radosavljevic M, Angermayr B, Datz C, et al. Austrian consensus on the definition and treatment of portal hypertension and its complications (Billroth II). Wien Klin Wochenschr. 2013;125(7-8):200-19.

25. Reiberger T, Ferlitsch A, Payer BA, et al. Noninvasive screening for liver fibrosis and portal hypertension by transient elastography - a large single center experience. Wien Klin Wochenschr. 2012;124(11-12):395-402.

26. Schwabl P, Bota S, Salzl P, et al. New reliability criteria for transient elastography increase the number of accurate measurements for screening of cirrhosis and portal hypertension. Liver Int. 2015;35(2):381-90.

27. Wang JB, Abnet CC, Chen W, et al. Association between serum $25(\mathrm{OH})$ vitamin $\mathrm{D}$, incident liver cancer and chronic liver disease mortality in the linxian nutrition intervention trials: a nested case-control study. Br J Cancer. 2013;109(7):1997-2004.

28. Wong GL, Chan HL, Chan HY, etal. Adverse effects of vitamin d deficiency on outcomes of patients with chronic hepatitis B. Clin Gastroenterol Hepatol. 2015;13(4):783-790.e1.

29. Lai JC, Bikle DD, Lizaola B, et al. Total $25(\mathrm{OH})$ vitamin D, free $25(\mathrm{OH})$ vitamin $\mathrm{D}$ and markers of bone turnover in cirrhotics with and without synthetic dysfunction. Liver Int. 2015; doi:10.1111/liv.12819. 